\title{
The role of hyperlipidemia therapy in preventive care
}

\author{
JEFFREY M. BLEICHER, DO
}

The diagnosis and treatment of lipid disorders have progressed significantly within the last several years. The ability to define the exact metabolic derangement is now possible using sophisticated laboratory techniques. For the practitioner and the patient, however, the precise characterization of the underlying disorder is not always necessary. With a basic understanding of the approach to lipid disorders as outlined, and the accurate determination of the cholesterol and triglyceride levels, the physician can outline a potent strategy for the reduction of lipids in his or her patients. At present, multiple therapeutic options are available to the physician. These are discussed.

Evidence linking the elevation of serum cholesterol levels to atherogenesis is now firmly established. ${ }^{1-3}$ A significant amount of data that demonstrates that treatment of hypercholesterolemia leads to a decline in the incidence of coronary artery disease has been accumulated. ${ }^{4}$ Additional data suggest that such treatment should begin in childhood. ${ }^{5}$

Since the completion of the Lipid Research Clinics Coronary Primary Prevention Trials,${ }^{6}$ hypercholesterolemia has become an issue of paramount importance in preventive medicine and remains a focus of intensive epidemiologic research. To assist physicians in the Fort Worth community to keep abreast of recent advances in this field of medicine, ${ }^{7}$ the Texas College of Osteopathic Medicine (TCOM) founded the Heart Disease Prevention Clinic. This clinic is based on the model of Frohlich, ${ }^{8}$ who gradually expanded a small local clinic to a national referral center for blood lipid disorders in western Canada. The clinic at TCOM is designed to diagnose and treat plasma lipid abnormalities and to operate a clinical research pro- gram. This article will review relevant aspects of lipid metabolism and summarize the approach taken in our clinic in managing these disorders.

\section{Diagnosis}

Hyperlipidemia is an increase in the plasma cholesterol or plasma triglyceride level or both beyond established normal limits. Until recently, severe hypercholesterolemia and moderate hypercholesterolemia have been defined as plasma cholesterol concentrations exceeding the 90 th percentile and 75 th percentile, respectively. Tables 1-3 show the new parameters for cardiovascular risk as recommended by the National Cholesterol Education Program of the National Heart, Lung and Blood Institute. ${ }^{4}$ Treatment should be initiated at the level of moderate risk.

The cholesterol values shown in Table 3 fall within the normal range of data sheets currently used by many commerical laboratories. Therefore, many patients who have not been classified previously as hyperlipidemics are, in fact, at risk for premature coronary artery disease.

Once cholesterol elevation is detected, medical evaluation is begun. A detailed family history is obtained first to ascertain whether other family members are affected similarly. ${ }^{9}$ For a man, the risk of myocardial infarction (MI) is increased fiveto seven-fold if his father suffered MI before the age of 55 or his mother before age 65 . For a woman, there is a 2.5- to seven-fold increase in risk when one parent has had premature MI. ${ }^{10}$

These epidemiologic data emphasize the importance of examining offspring of affected families, because they may indicate primary lipid disorders that have a genetic basis. Familial histories of xanthomas and diabetes mellitus also are elicited. The history taking is then directed toward systemic disorders that affect lipid metabolism, as shown in Table 4.

The diagnosis of hyperlipidemia associated with systemic diseases does not exclude the possiblity 
TABLE 1. CORONARY HEART DISEASE RISK FACTORS.*

Gender-Male sex

Family history - coronary disease events prior to 55 years of age in a parent or sibling

Cigarette smoking - currently smoking more than 10 cigarettes/day

Hypertension - elevated blood pressure using JNC III guidelines

Low HDL-cholesterol-levels $<35 \mathrm{mg} / \mathrm{dl}$ (for treatment, not screening decisions)

Diabetes mellitus

History of stroke or peripheral vascular disease

Obesity $-30 \%$ or more overweight

*Reprinted from Archives of Internal Medicine (1988; 36-69).

\begin{tabular}{|c|c|c|}
\hline Total cholesterol & Classification & LDL-cholesterol \\
\hline $\begin{array}{l}<200 \mathrm{mg} / \mathrm{dl} \\
200 \text { to } 239 \mathrm{mg} / \mathrm{dl} \\
\geq 240 \mathrm{mg} / \mathrm{dl}\end{array}$ & $\begin{array}{c}\text { Desirable } \\
\text { Borderline-high } \\
\text { High }\end{array}$ & $\begin{array}{c}<130 \mathrm{mg} / \mathrm{dl} \\
130 \text { to } 159 \mathrm{mg} / \mathrm{dl} \dagger \\
\geq 160 \mathrm{mg} / \mathrm{dl}\end{array}$ \\
\hline
\end{tabular}

of an underlying primary disorder. Therefore, the patient is reexamined once the secondary (systemic) disorder has been brought under control (generally, three to six months after the initiation of treatment). Further, some secondary disorders, such as uremia, require specialized attention, because the lipid disorder often does not remit with either hemodialysis or peritoneal dialysis. ${ }^{11}$

The history is completed by data on diet and lifestyle. An extensive dietary history is obtained to ascertain excessive caloric, alcohol, or saturated fat intake that requires modification. The patient records everything eaten during a three-day period on a food intake record sheet. The diary includes the time of the day when each meal was taken, the type and amount of food eaten, and the mode of preparation. The food intake data are analyzed by a registered dietician for the total number of calories consumed and the distribution of the intake among the macronutrients (proteins, carbohydrates, and fats). The amounts of cholesterol, vitamins, and minerals (especially table salt) also are computed.

An exercise history is obtained to assess the degree of aerobic fitness. Although exercise does not affect primary lipid disorders appreciably (MS Brown, MD, "You can't outrun cholesterol," medical grand rounds, Parkland Memorial Hospital, Dallas, 1986), it may be important in improving the sense of well-being for the patient, may promote compliance with medical therapy, and may aid in elevating high-density lipoprotein (HDL) levels. ${ }^{12}$

Physical examination is directed toward two areas: (1) the stigmata of hyperlipidemia (xanthomas, arcus senilis, and hepatic enlargement or sple- nomegaly); and (2) assessment of the ravages of atherosclerosis. A baseline ECG also is obtained, and patients older than 35 years should undergo stress testing before an exercise regimen is recommended.

Laboratory examination involves a series of steps indicated by the history and physical examination. Considerable importance is placed on laboratory values, for the same reason that accurate blood pressure determinations are considered crucial-to avoid committing an apparently healthy patient to lifelong medical therapy based on erroneous data. Most important are accurate and reliable (reproducible) cholesterol, HDL-cholesterol, and triglyceride determinations. We have found that commercial and hospital laboratories often have provided data that were not accurate enough for a precise diagnosis; consequently, we now perform all lipid determinations in our own laboratory, which conforms to Lipid Research Clinics standards. ${ }^{5}$

The laboratory diagnostic strategy is based mainly on serum lipid determinations following a 14-hour fast. Observing the serum after overnight storage at $4^{\circ} \mathrm{C}$ allows the assessment of exogenous hypertriglyceridemia (presence of chylomicrons). Under some circumstances (with type III disease), agarose gel electrophoresis also is carried out to identify the broad $\beta$ band. Further specific tests may be performed to make the exact etiologic diagnosis of a particular inherited lipid disorder. ${ }^{13}$

These include isoelectric focusing of apolipoproteins, immunoassays for apolipoproteins, plasma enzyme assays, ultracentrifugal analysis of lipoproteins, and access to gene probes for apoprotein analysis.

Clinical management of the patient is started with Fredrickson's classification. This system is used to establish the presence of a specific lipid pattern (Table 5$)^{13}$ but not to identify the underlying cause. Such an approach may be misleading, especially with a patient under treatment. The diagnosis of lipid disorders is akin to the diagnosis of anemia-both are symptoms of respective underlying diseases, not diagnoses unto themselves. This is particularly true for the primary lipid disorders because they are of genetic origin, and, thus, they may affect several family members simultaneously. The function of the laboratory of our Heart Disease Prevention Clinic is to assist in developing a specific diagnosis, as listed in Table 5.

\section{Major classes of hyperlipidemia}

Type 1 hyperlipidemia is distinguished clinically by grossly lipemic serum chylomicron accumulation in the fasting state. Normally, chylomicrons are secreted into the circulation after a meal. The 

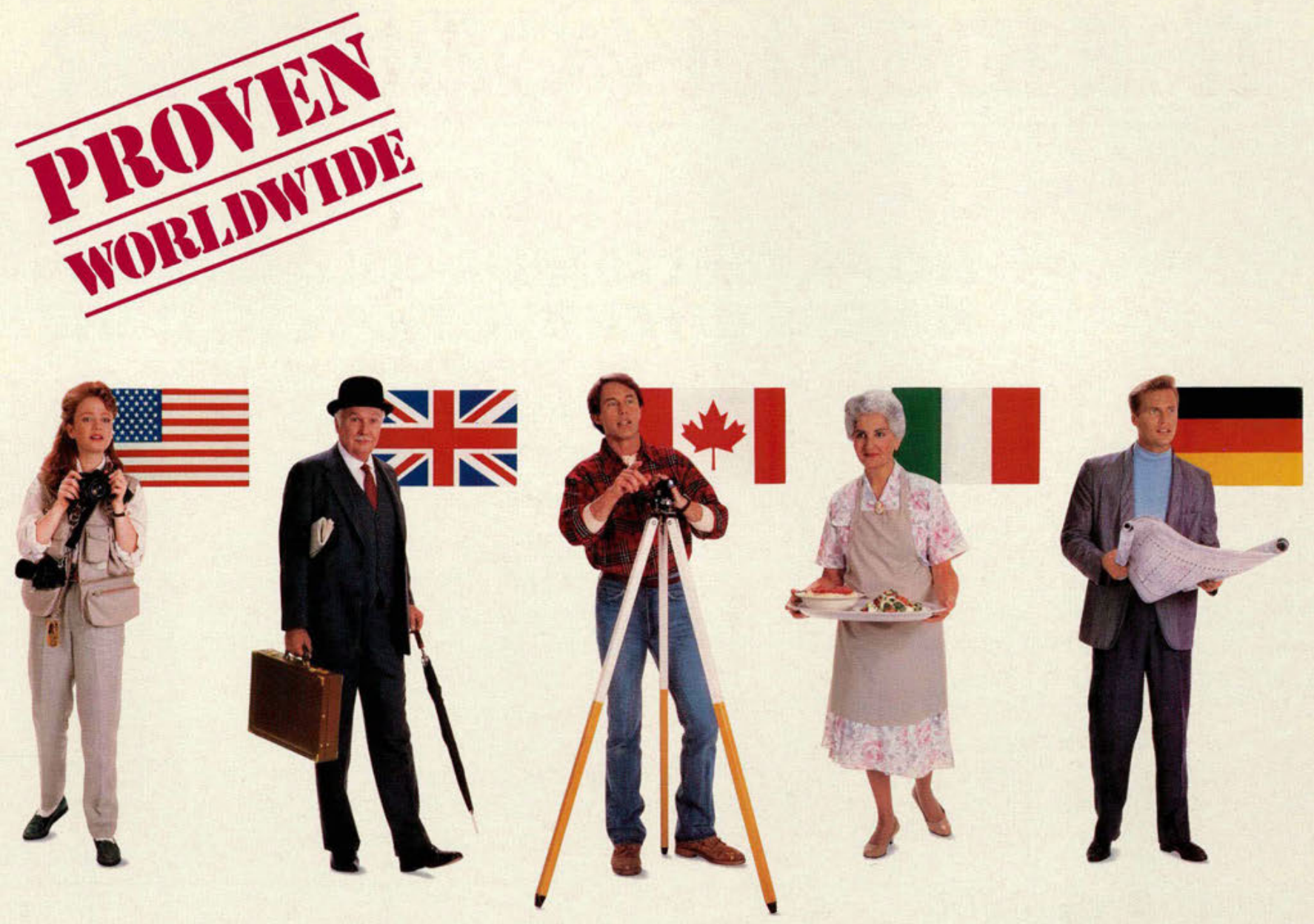

\section{FAST, UNSURPASSED RELIEF \\ THAT LETS PATIENTS STAY ALERT SO THEY CAN PERFORM AT THEIR BEST}

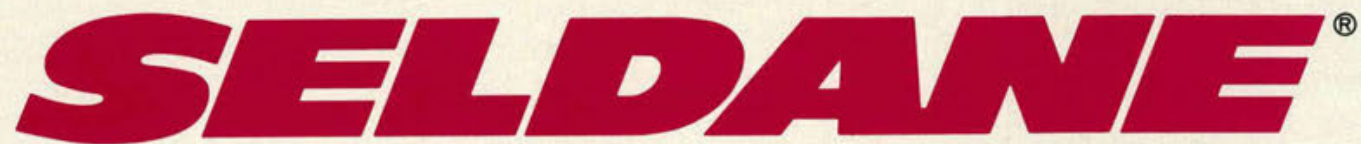

(terfenadine) $60 \mathrm{mg}$ tablets BID for seasonal allergic rhinitis

The \#1 prescribed allergy product in the U.S. and around the world* 


\section{THE IDEAL PROFILE FOR}

\section{NO ANTIHISTAMINE-OLD OR NEW- IS MORE EFFECTIVE THAN SELDANE (terfenadine)}

\section{Maximum relief}

Twenty-nine well-designed, doubleblind, controlled clinical studies have compared Seldane with antihistamines used around the world. These studies, involving 3,541 patients - plus steadily growing worldwide use now totaling more than 41 million patientmonths of experience - show that Seldane is unsurpassed in efficacy. ${ }^{1-5}$

\section{No development of tolerance}

Seldane has been proven effective in through-the-season use without development of tolerance in four long-term clinical studies, ${ }^{5-8}$ one lasting six months.

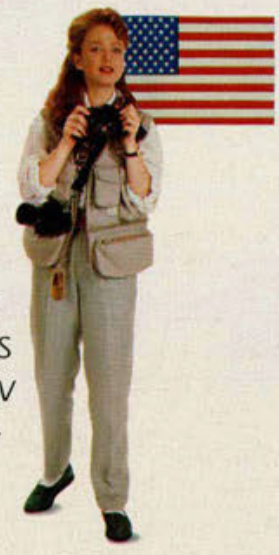

\section{Rapid relief}

The rapid action of Seldane has been shown both in clinical studies ${ }^{5.9}$ and histamine-induced skin wheal tests. ${ }^{5.10 .11}$ Most hay fever patients (55\%) experienced relief within 1 hour, and 84\% within 2 hours, after Seldane administration. Seldane produced more than $50 \%$ reduction of skin wheal area within 1 to 2 hours and $90 \%$ reduction within 4 hours, as shown below. ${ }^{10}$
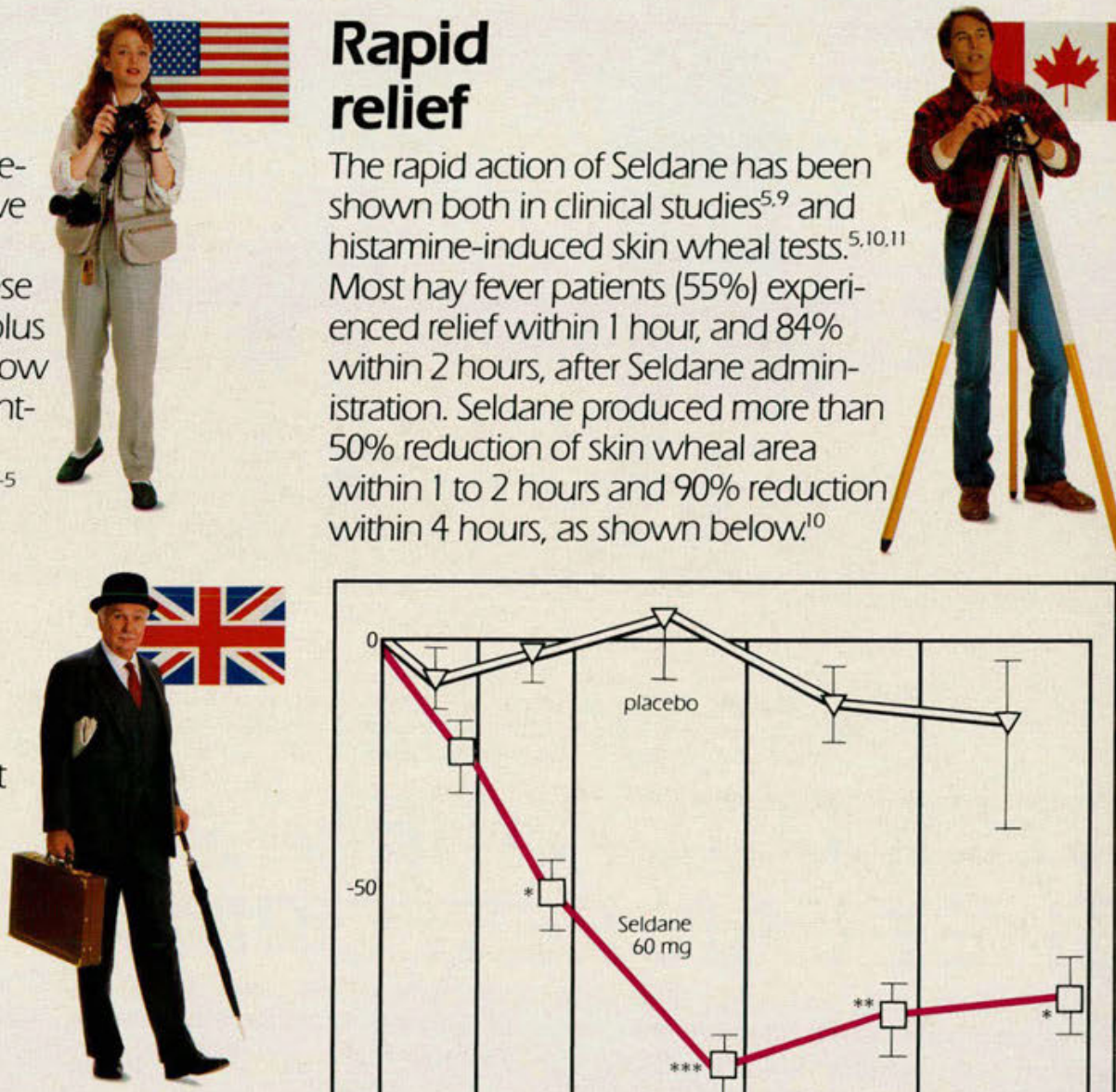

Percent change in histamine wheal area resulting from a single dose of

Seldane $60 \mathrm{mg}$ or placebo. ${ }^{10}$

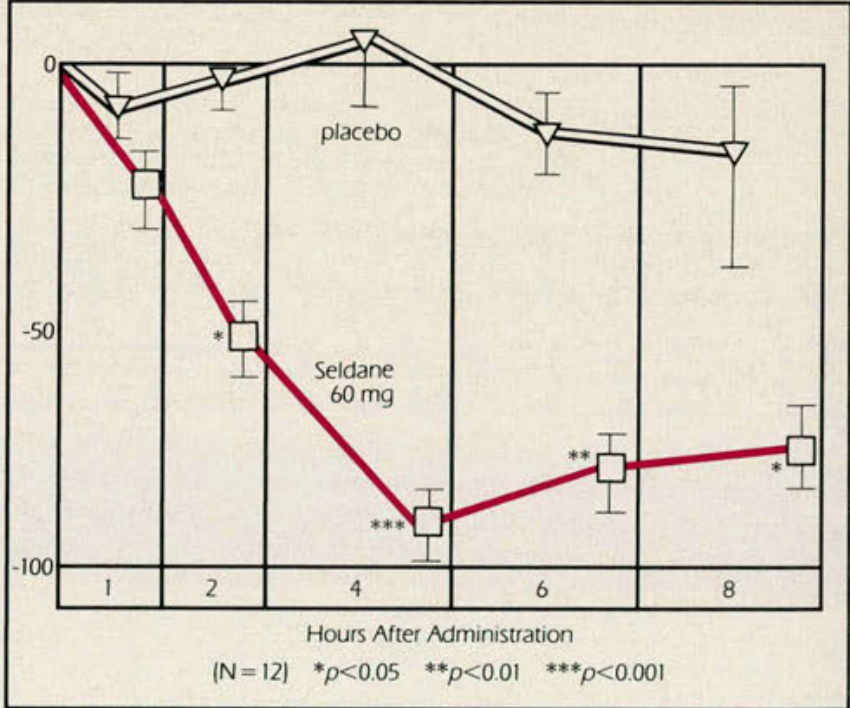

\section{THE \# 1 PRESCRIBED ALLERGY PRODUCT IN THE U.S. AND AROUND THE WORLD}




\section{FAST, ON-THE-JOB RELIEF}

\section{LETS PATIENTS STAY ALERT SO THEY CAN PERFORM AT THEIR BEST}

\section{Comparable to placebo in drowsiness** and CNS effects}

Seldane is comparable to placebo in CNS effects, such as drowsiness, EEG activity, multiple sleep latency tests, and self-rated alertness. ${ }^{5,12,13}$ Even at 5 times the usual daily dose (600 mg in single or multiple doses) for up to 10 weeks, Seldane showed no sedative effect greater than that of placebo. ${ }^{5}$

See Prescribing Information for Contraindications, Precautions and Adverse Reactions.

\section{Proven patient preference}

$87 \%$ of patients who start on Seldane refill their Seldane prescription, according to a nationwide study of nearly a thousand members of large-group prescription plans. Only $59 \%$ of those started on the next leading antihistamine refilled. ${ }^{5}$ In a major U.S. consumer study, $87 \%$ of patients said that Seldane worked as well as or better than other allergy medications previously taken. $163 \%$ said that Seldane worked better. $\left.\right|^{5}$

\section{Convenient dosing for high compliance}

Patients take Seldane only twice daily at any convenient 12-hour intervala regimen that promotes high patient compliance.

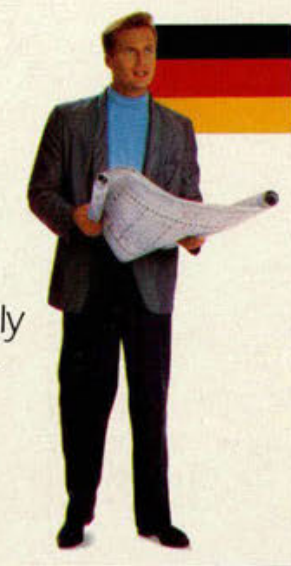

Percent patient compliance by dosage schedule

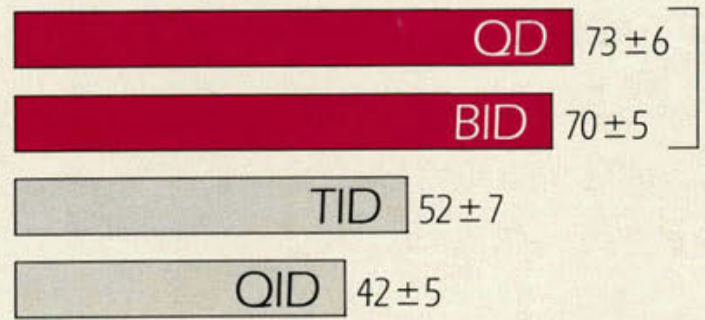

N.S.

PERCENT COMPLIANCE

\begin{tabular}{lllllllllll}
\hline 0 & 10 & 20 & 30 & 40 & 50 & 60 & 70 & 80 & 90 & 100
\end{tabular}

A summary of 26 studies relating compliance and dosage schedules of various types of medications showed no significant difference in compliance rates between q.d. and b.i.d. dosing. There was significantly greater compliance with q.d. or b.i.d. dosing compared to ti.d. or q.i.d. dosing $(\rho<0.05)^{14}$
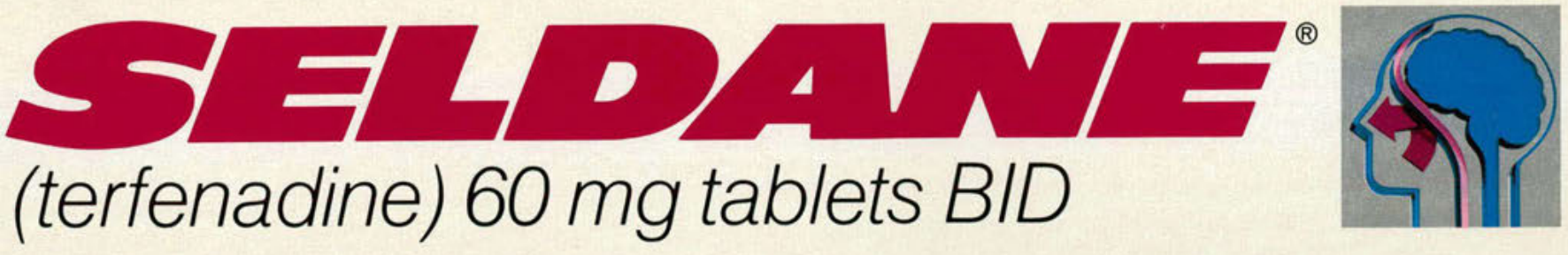

**The incidence of drowsiness reported in controlled clinical studies with Seldane $60 \mathrm{mg}$ b.i.d. did not differ significantly from placebo, while chlorpheniramine 4 mg ti.d./q.i.d. produced twice the incidence $(\rho<0.02)$.

Before prescribing Seldane, please see Brief Summary of Prescribing Information which follows this advertisement. 


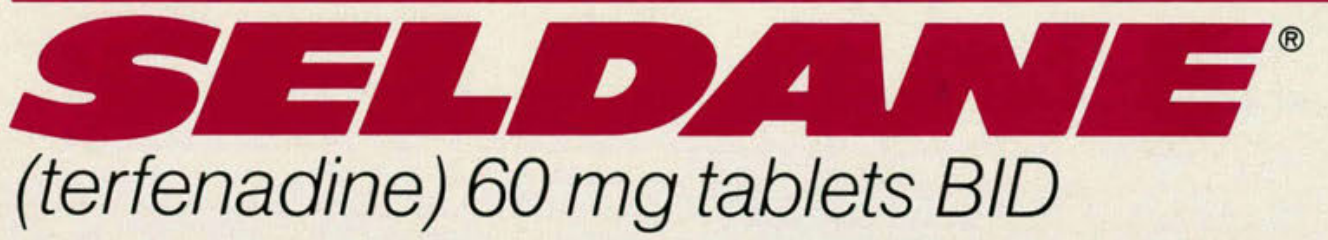

\section{The \#1 prescribed allergy product in the U.S. and around the world...now with more than 41 million patient-months of experience}

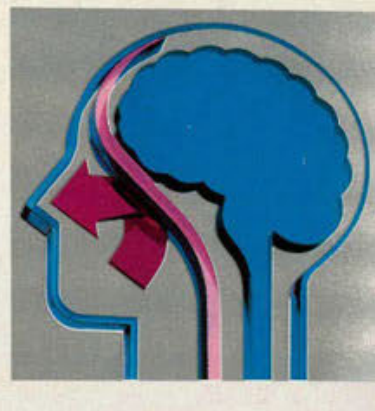

\section{FAST, UNSURPASSED RELIEF THAT LETS PATIENTS STAY ALERT SO THEY CAN PERFORM AT THEIR BEST}

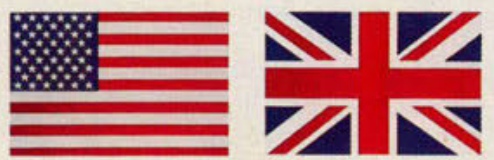

Seldane ${ }^{\circledR}$ (terfenadine) $60 \mathrm{mg}$ Tablets

CAUTION: Federal law prohibits dispensing without prescription.

DESCRIPTION

Seldane (terfenadine) is available as tablets for oral administration. Each tablet contains $60 \mathrm{mg}$ terfenadine. Tablets also contain, as inactive ingredients: corn starch, gelatin, lactose, magnesium stearate, and sodium bicarbonate.

INDICATIONS AND USAGE

Seldane is indicated for the relief of symptoms associated with seasonal allergic minitis such as sneezing, rhinorrhea, pruritus, and lacrimation.

CONTRAINDICATIONS

Seldane is contraindicated in patients with a known hypersensitvity to terfenadine or any of its ingredients.

PRECAUTIONS

Information for patients

Patients taking Seldane should receive the following information and instructions. Antihistamines are prescribed to reduce allergic symptoms. Patients should be questioned about pregnancy or lactation before starting Seldane therapy, since the drug should be used in pregnancy or lactation only if the potential benefit justifies the potential risk to fetus or baby. Patients should be instructed to take Seldane only as needed and not to exceed the prescribed dose. Patients should also be instructed to store this medication in a tightly closed container in a cool, dry place, away from heat or direct sunlight, and away from children

Carcinogenesis, mutagenesis, impairment of fertility

Oral doses of terfenadine, corresponding to 63 times the recommended human daily dose, in mice for 18 months or in rats for 24 months, revealed no evidence of tumorigenicity. Microbial and micronucleus test assays with terfenadine have revealed no evidence of mutagenesis.

Reproduction and fertility studies in rats showed no effects on male or female fertility at oral doses of up to 21 times the human daily dose. At 63 times the human daily dose there was a small but significan reduction in implants and at 125 times the human daily dose reduced implants and increased post-implantation losses were observed, which were judged to be secondary to maternal toxicity.

Pregnancy Category $C$

There was no evidence of animal teratogenicity. Reproduction studies have been performed in rats at doses 63 times and 125 times the human daily dose and have revealed decreased pup weight gain an survival when terfenadine was administered throughout pregnancy and lactation. There are no adequate and well-controlled studies in pregnant women. Seldane should be used during pregnancy only if the potential benefit justifies the potential risk to the fetus.

Nonteratogenic effects

Seldane is not recommended for nursing women. The drug has caused decreased pup weight gain and survival in rats given doses 63 times and 125 times the human daily dose throughout pregnancy and lactation. Effects on pups exposed to Seldane only during lactation are not known, and there are no adequate and well-controlled studies in women during lactation.

Pediatric use

Safety and effectiveness of Seldane in children below the age of 12 years have not been established. General

Consideration should be given to potential anticholinergic (drying) effects in patients with lower airway disease, including asthm

ADVERSE REACTIONS

Experience from clinical studies, including both controlled and uncontrolled studies involving more than 2,400 patients who received Seldane, nrovides information on adverse experience incidence for periods number of patients, the dose was as low as $20 \mathrm{mg}$ twice a day, or as high as $600 \mathrm{mg}$ daily
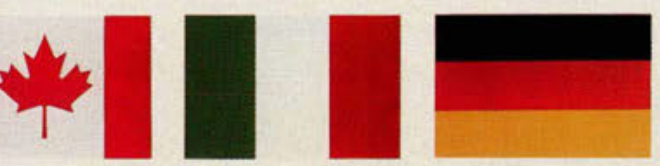

adverse effects in

ADVERSE EVENTS REPORTED IN CLINICAL TRIALS

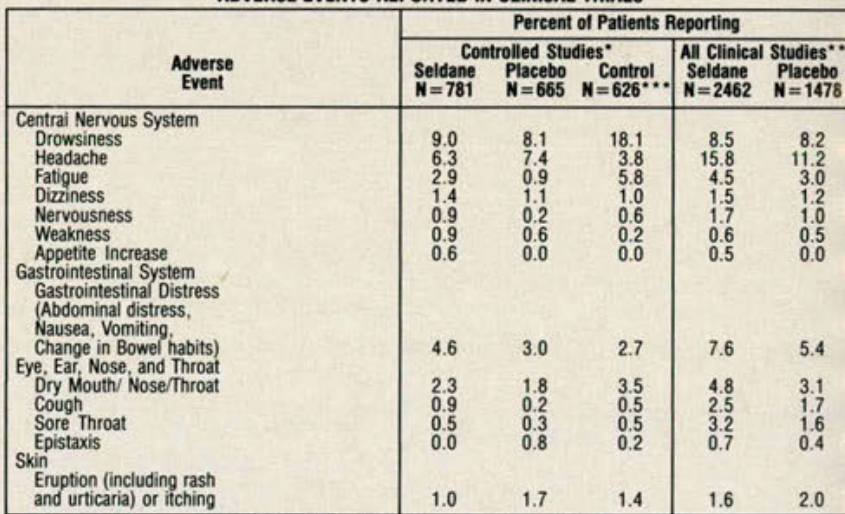

"Duration of treatment in "CONTROLLED STUDIES" was usually 7-14 DAYS.

- Duration of treatment in "ALL CLINICAL STUDIES" was up to 6 months. patients)

In addition to the more frequent side effects reported in clinical trials (See Table), adverse effects ha been reported at a lower incidence in clinical trials and/or spontaneously during marketing of Selda that warrant listing as possibly associated with drug administration. These include: alopecia, (hair lo or thing), anaphylaxis, angioedema, arthythmia (including ventricular tachyarmythmia), bro dysmasm, con dysmenorimea), musculoskeletal symptoms, nightmares, palpitation, paresthesia, photosensituvity, pr longed Qr interval, seizures, sweating, syncope, tachycardia, tremor, urinary irequency, and visu disturances. In clical trals, several instances of

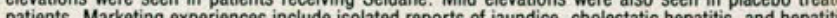
patients. Marketing experiences include isolated reports of jaundice, cholestatic hepatitis, and hepatiti in most cases avallable information is incomplete. In neither the clinical trials nor marketing experien

OVERDOSAGE

Information concerning possible overdosage and its treatment appears in Full Prescribing Information DOSAGE AND ADMINISTRATION

The usual dosage for adults and children 12 years and older is $60 \mathrm{mg}$ (1 tablet) twice daily.

Product Information as of June, 1988

MERRELL DOW PHARMACEUTICALS INC.

Subsidiary of The Dow Chemical Company
Cincinnati, Ohio 45215, U.S.A.

Merrell Dow

PRINTED IN U.S.A

References: 1. Kemp JP, Buckley CE, Gershwin ME, et al: Multicenter, double-blind, placebo-controlled trial of terfenadine in seasonal allergic rhinitis ánd conjunctivitis. Ann Allergy 54:502-509, 1985. 2. Backhouse CI, Brewster BS, Lockhart JDF, et al: Terfenadine in allergic rhinitis. A comparative trial of a new antihistamine versus chlorpheniramine and placebo. Practitioner 226:347-348, 351, 1982. 3. Buckley CE, Buchman E. Falliers CJ, et al: Terfenadine treatment of fall hay fever. Ann Allergy 60:123-128, 1988. 4. Melillo G, D'Amato G, Zanussi C, et al: A multicentre controlled trial of terfenadine, dexchlorpheniramine, and placebo in allergic rhinitis. Arzneim-Forsch/Drug Res 32:1202-1203, 1982. 5. Data available upon request, MERRELL DOW PHARMACEUTICALS INC., Cincinnati. Ohio 45215. 6. Gastpar H. Dieterich HA: Prophylaxis of seasonal allergic rhinitis with a new antihistaminic drug. Arzneim-Forsch/Drug Res 32:1209-1211, 1982. 7. Gastpar H. Dieterich HA: Comparative study of the efficacy and tolerance of terfenadine and clemastine in patients with seasonal allergic rhinitis. Arzneim-Forsch/Drug Res 32:1211-1213, 1982. 8. Krause LB. Shuster S: The effect of terfenadine on dermographic wealing. Br J Dermatol 10:73-79, 1984. 9. Murphy-O'Connor JC, Renton RL. Westlake DM, et al: Comparative trial of two dose regimens of terfenadine in patients with hay fever. J Int Med Res 12:333-337, 1984. 10. Hüther KJ, Renftle G. Barraud N, et al: Inhibitory activity of terfenadine on histamine-induced skin wheals in man. Eur J Clin Pharmacol 12:195-199, 1977. 11. Reinberg A Levi F, Guillet P, et al: Chronopharmacological study of antihistamines in man with special references to terfenadine. Eur J Clin Pharmacol 14:245-252, 1978. 12. Roehrs TA, Tietz El, Zorick FJ, et al: Daytime sleepiness and antihistamines. Sleep 7:137-141, 1984. 13. Fink M, Irwin P: CNS effects of the antihistamines diphenhydramine and terfenadine (RMI 9918). Pharmakopsychiat 12:35-44, 1979. 14. Greenberg RN: Overview of patient compliance with medication dosing: a literature review Clin Therapeutics 6:592-599, 1984 
plasma triglyceride level is $>1,000 \mathrm{mg} / \mathrm{dL}$ in this disorder. Type I hyperlipidemia often is associated with lipemia retinalis, recurrent episodes of abdominal pain, high risk of pancreatitis, and eruptive xanthomatosis of the skin. ${ }^{14}$

The primary cause of the disease is either a congenital deficiency of lipoprotein lipase or apolipoprotein C-II. Lipoprotein lipase is an enzyme located on the surface of capillary endothelial cells; it is responsible for the breakdown of very-lowdensity lipoprotein (VLDL) and chylomicrons, which are triglyceride transporting particles. ${ }^{14} \mathrm{Apo}-$ lipoprotein C-II (a normal component of triglyceride-rich lipoproteins) is necessary for the functioning of lipoprotein lipase.

This disorder requires careful attention to the level of circulating triglycerides. Although severe hypertriglyceridemia generally is not associated with accelerated atherosclerosis, the recurrent episodes of pancreatitis that often accompany it exposes the patient to considerable morbidity.

Type II hyperlipidemia is an elevation in cholesterol secondary to low-density lipoproteins (LDL) accumulation in the blood, with or without triglyceride elevation. LDL is the main transporter of cholesterol in plasma. Cholesterol is needed to manufacture hormones and cellular membranes and, therefore, is necessary for life. Peripheral and hepatic cells are able to remove LDL particles from the blood via cell surface receptors. The work of Nobel prize laureates Goldstein and Brown ${ }^{15}$ has shown that some individuals lack the gene for functional LDL receptors and are unable to clear their plasma cholesterol without medical therapy. This condition is known as familial hypercholesterolemia (FH).

An autosomal dominant trait, $\mathrm{FH}$ occurs in the random population at the rate of 1 in 500 heterozygotes. ${ }^{15}$ The serum cholesterol level usually is in the range of 350 to $500 \mathrm{mg} / \mathrm{dL}$. These patients inherit a gene that is a mutant, whereas the normal gene pair encodes for LDL receptors in the liver and in peripheral tissues. ${ }^{15}$ These receptors are nec-

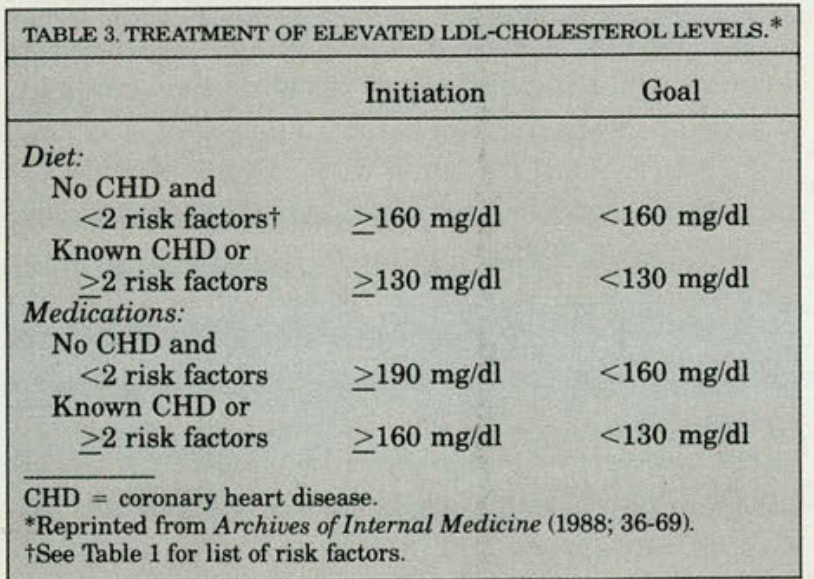

essary to remove cholesterol from the circulation. When only a mutant gene is inherited (heterozygote), an approximately two-fold elevation in LDL is observed; this may lead to heart attacks in persons as young as 35 years.

Homozygotes, who are found at a frequency of 1 per $1,000,000$ general population, have no detectable LDL receptors; they ultimately require liver transplants for survival. These patients develop advanced coronary artery disease as early as the first year of life.

Lack of diagnosis of this type II disorder often leads to mistreatment. General risk-reduction maneuvers, such as diet and excercise, cannot significantly influence the cholesterol levels. Therefore, life-long drug therapy is required, even for $\mathrm{FH}$ heterozygotes.

Another possible cause of Fredrickson's type II pattern is familial combined hyperlipidemia, which is thought to be caused by overproduction of apoprotein B. ${ }^{16}$ This condition is characterized by an elevation of both cholesterol and triglyceride levels. It is of genetic origin, although the exact mode of transmission is unknown. This disorder may be expressed differently within members of the same family, with some having type II and some type IV patterns. Goldstein and associates ${ }^{16}$ found this to be the most common lipid disorder in survivors of myocardial infarction; it may be present in $10 \%$ of all patients with coronary artery disease. Unlike familial hypercholesterolemia, tendon xanthomas are rare, as is elevation of cholesterol levels in childhood.

The type III pattern is also known as broad $\beta$ disease because of its unique electrophoretic pattern. Clinically, it is characterized by yellowish fat deposits in the creases of the palms and xanthomas over the elbows and tibial tuberosities. Both serum cholesterol and triglyceride values are elevated, with the triglycerides being higher because of difficulty in metabolizing a unique cholesterolrich VLDL, which results from an apolipoprotein defect. ${ }^{17}$

\begin{tabular}{|ll|}
\hline $\begin{array}{l}\text { TABLE 4. SYSTEMIC DISEASES OFTEN ASSOCIATED WITH HYPER- } \\
\text { LIPIDEMIA. }\end{array}$ \\
\hline Diabetes & Uremia \\
Hypothyroidism & Nephrotic syndrome \\
Biliary obstruction & Hepatitis \\
$\begin{array}{l}\text { Multiple myeloma } \\
\text { Systemic lupus } \\
\text { erythematosus }\end{array}$ & Alcoholism \\
Cushing's syndrome & Excessive estrogen levels \\
\hline
\end{tabular}




\begin{tabular}{|c|c|c|c|}
\hline $\begin{array}{l}\text { Increased } \\
\text { chylomicrons } \\
\text { (types I and V HLP*) }\end{array}$ & $\begin{array}{l}\text { Increased VLDL* } \\
\text { (type IV HLP) }\end{array}$ & $\begin{array}{l}\text { Increased } \beta \text {-VLDL* } \\
\text { (type III HLP) }\end{array}$ & $\begin{array}{l}\text { Increased LDL* } \\
\text { (type II HLP) }\end{array}$ \\
\hline $\begin{array}{l}\text { Familial hypertrigly- } \\
\text { ceridemia }\end{array}$ & $\begin{array}{l}\text { Familial hyper- } \\
\text { triglyceridemia }\end{array}$ & $\begin{array}{l}\text { Apolipoprotein } \\
\text { E2 phenotype }\end{array}$ & $\begin{array}{l}\text { Familial hyper- } \\
\text { cholesterolemia }\end{array}$ \\
\hline $\begin{array}{l}\text { Familial combined } \\
\text { hyperlipidemia } \\
\text { (increased chylomicrons) }\end{array}$ & $\begin{array}{l}\text { Familial combined } \\
\text { hyperlipidemia }\end{array}$ & $\begin{array}{c}\text { Apolipoprotein } \\
\text { E variants }\end{array}$ & $\begin{array}{l}\text { Familial combined } \\
\text { hyplipidemia }\end{array}$ \\
\hline $\begin{array}{l}\text { Lipoprotein lipase } \\
\text { deficiency }\end{array}$ & & $\begin{array}{c}\text { Apolipoprotein } \\
\text { E deficiency }\end{array}$ & \\
\hline $\begin{array}{l}\text { Apolipoprotein } \\
\text { C-II deficiency }\end{array}$ & & & \\
\hline
\end{tabular}

Normally, chylomicrons are converted to cholesterol-rich remnant particles by the action of lipoprotein lipase and subsequently are removed from the circulation by the liver. The liver uses the lipids transported in chylomicron remnants and secretes another triglyceride-rich VLDL. This VLDL is cleared from the plasma by lipoprotein lipase; first, it is converted to intermediate density lipoprotein (IDL) and then to LDL. The molecular defect in type III hyperlipidemia is caused by an altered form of apolipoprotein $\mathrm{E}$, which results in inefficient hepatic uptake and, thus, excessive accumulation of IDL in the plasma. These patients are also at risk for premature coronary artery disease. The disorder is more common in men than in women, perhaps because of a protective effect of estrogen. ${ }^{17}$

Type IV hyperlipidemia genetically results from a disorder referred to as familial endogenous hypertriglyceridemia, with triglyceride levels in the range of 300 to $1,000 \mathrm{mg} / \mathrm{dL}$. The type IV pattern is due to either overproduction of VLDL ${ }^{18}$ or difficulty in its clearance from the circulation, which is secondary to either a lipoprotein lipase or apoprotein deficiency similar to the type I disorder. Type IV hyperlipidemia does not appear to be an independent risk factor for coronary artery disease. However, it often is particularly troublesome in people with secondary causes of hyperlipidemia, such as those listed in Table 4.

The type V pattern also has a genetic basis possibly related to an apolipoprotein deficiency. ${ }^{13} \mathrm{It}$ is characterized by elevated triglycerides with chylomicrons in the serum. Diagnosis and clinical sequelae are similar to those in the type 1 pattern. This disorder commonly is associated with hyper- tension, polyneuropathies, hyperuricemia, and diabetes mellitus. ${ }^{19}$

\section{Treatment}

Diet is the first step in the treatment of hyperlipidemic disorders. Patients in the moderate risk category often can be treated by diet alone, whereas those at high risk are likely to need concomitant lipid-lowering medication. The diet recommended by the American Heart Association ${ }^{20}$ generally is effective. This regimen includes reducing fat to $30 \%$ of total caloric intake, with no more than $300 \mathrm{mg}$ of total cholesterol ingested per day. If the patient is obese, decreased caloric intake to effect weight reduction also is recommended. More liberal fat intake, to give the diet more flexibility or to meet a budget, may be allowed in the form of monounsaturated fats, such as olive oil. ${ }^{21}$ Fats from vegetables are preferable to meat sources ${ }^{22}$ and may be less expensive. A vegetarian diet high in polyunsaturated fat also is desirable. ${ }^{23}$ With the compliance with recommended diets remaining highly variable,${ }^{1}$ this area needs much further investigation. The suggestions made here are examples of how a higher level of compliance may be reached.

Children of patients at risk should be screened and started on a modified diet at an early age, as recommended by the American Heart Association $^{20}$ : (1) The diet should be nutritionally adequate; (2) caloric intake should be adjusted for growth rate, activity, and weight; (3) total fat should be restricted to $30 \%$ of caloric intake $(10 \%$ saturated, $10 \%$ polyunsaturated, and $10 \%$ monosaturated fat); (4) cholesterol should be limited to $100 \mathrm{mg} / 1,000 \mathrm{kcal}$, with an upper limit of $300 \mathrm{mg} /$ day; (5) protein should provide $15 \%$ of calories; (6) 
carbohydrate should provide $55 \%$ of calories; and (7) salt should not be used at the table.

Because the human body can synthesize adequate amounts of endogenous cholesterol from other nutrients, diet is the cornerstone of any treatment. Samuel and associates ${ }^{24}$ have provided a balanced review of dietary recommendations.

Drug treatment presently includes three types of medications taken alone or in combination. For elevated cholesterol (type II hyperlipidemia), treatment generally consists of a bile acid binding resin (cholestyramine or colestipol). These agents act by trapping bile acids in the intestine, which interrupts the enterohepatic circulation. Consequently, increased hepatic synthesis of bile acids from its precursor, cholesterol, is required. The liver, therefore, removes more cholesterol from the circulation, and serum cholesterol levels are lowered. This therapy has been demonstrated by the Lipid Research Clinics ${ }^{6}$ to reduce the incidence of coronary artery disease and generally has few (if any) longlasting side effects.

Short-term side effects are encountered occasionally. The most common are gastrointestinal problems, especially constipation and bloating. Both cholestyramine and cholestipol bind anionic drugs, including digoxin, thyroxine sodium warfarin, and thiazide diuretics. Additionally, these agents may cause an increase in plasma triglyceride levels, as well as elevated alkaline phosphatase and transaminase values. ${ }^{25}$

Another agent that has been used to lower cholesterol is probucol. While this agent has been found to lower LDL cholesterol, it has also been found to lower HDL cholesterol at the same time. ${ }^{26}$ Where the balance lies between one beneficial effect and one possible deleterious effect is unclear at present. The use of probucol may lie in synergism with other cholesterol agents, as probucol has been shown to have an antioxidant effect-the latter action may inhibit the deposition of LDL cholesterol in blood vessels independent of its cholesterol-lowering effects. This use, however, requires further study.

For those disorders involving either combined elevation of cholesterol and triglycerides or triglyceride elevation alone (types III, IV, and V), nicotinic acid is standard therapy. Nicotinic acid has been evaluated by the Coronary Drug Project, ${ }^{27}$ which found that it decreases the incidence of coronary events. Nicotinic acid has a number of side effects, the most annoying of which is flushing. This can be decreased by taking the drug with meals or one adult aspirin. The dose required for a significant hypolipidemic effect is approximately $3 \mathrm{~g} /$ day. To avoid side effects, a starting dose of 100 $\mathrm{mg}$ twice a day, which is increased by $100 \mathrm{mg}$ twice a day every three to five days to $1 \mathrm{~g} /$ day and then increased by $500 \mathrm{mg}$ increments, until the total dosage is reduced, is recommended. Mild elevation of uric acid may accompany this therapy, but it usually is asymptomatic. Glucose intolerance also may occur, which may require regulation of blood glucose levels in diabetics. In addition, there may be mild transaminitis, but this will not require discontinuation of the medication.

The third major drug currently available for the treatment of hyperlipidemia is gemfibrozil, which primarily is used for the treatment of type IV triglyceride disorders. The dosage is two $300-\mathrm{ml}$ tablets twice a day. The drug is well tolerated and can be combined with nicotinic acid for recalcitrant cases. Although other hypolipidemic drugs (clofibrate, dextrothyroxine, and neomycin) are available, several trials have shown these drugs to have side effects that limit their routine usage. ${ }^{25,27}$

Recently, gemfibrozil has been found to be beneficial in disorders involving cholesterol, whether or not the cholesterol elevation is accompanied by a derangement of triglycerides. In a randomized double-blind study involving 4081 men, gemfibrozil was found to significantly reduce the incidence of coronary events as compared to placebo, particularly those with both cholesterol and triglyceride elevations. ${ }^{28}$ It appears to reduce the incidence of heart disease through a beneficial effect on HDL. Consequently, gemfibrozil should be considered in the armamentarium of agents for cholesterol disorders as well. It will be most useful in those patients who cannot comply with the binding resins or who find the side effects of nicotinic acid intolerable. $^{29}$

The last year has also seen the first of a new class of lipid-lowering agents derived from fungal metabolites. These agents work by interfering with 3-hydroxy-3-methylglutaryl coenzyme A reductase (HMG CoA reductase), which is the liver's rate determining enzyme of cholesterol synthesis. ${ }^{25}$ The only agent in this class presently available for use is lovastatin. This is indicated for those disorders involving the cholesterol elevation without concomitant triglyceride problems. This agent has the advantage of being in pill form and can exert its lipidlowering effects even if taken once a day. While this agent may seem ideal for cholesterol disorders, there are some pertinent warnings. First, the drug does not have long-term survival data as does the binding resins. It is well known that two drugs that have the same effect may not have the same longterm benefit, as has been demonstrated in other blood pressure studies, for example. In taking lovastatin, one must be checked for cataracts, liver function abnormalities, and rhabdomyolysis on a regular basis, which can impose an additional ex- 
pense on top of an already expensive agent. While this agent may prove to be a powerful tool in the prevention of coronary artery disease, its use must be tempered by the above.

Presently, much investigation is directed toward the beneficial effects of fish oil in lowering triglyceride and cholesterol levels. There is recent interest in the potential therapeutic effects of fish oil in type II and type V hyperlipidemia, ${ }^{30}$ although the dose requirements have yet to be established. Overall, it is reasonable to ingest $3 \mathrm{~g}$ eicosapentaenoic acid (EPA) per day, either in supplement form or from fish itself ( $1 / 2 \mathrm{lb}$ of salmon), although smaller quantities also may prove effective. Studies to determine the effectiveness of lower doses currently are in progress. ${ }^{31}$

\section{Comment}

The diagnosis and treatment of lipid disorders is at the stage where the hypertension field was a generation ago. The awareness of these disorders is increasing rapidly in the medical profession, but, at present, there are relatively few pharmacologic agents available for treatment. In addition to the elevation of lipid levels, other plasma lipid abnormalities, such as lipoprotein deficiency syndromes, ${ }^{32}$ may have serious clinical consequences.

\section{Summary}

The treatment of hyperlipidemia is undergoing rapid evolution. Recently, a more stringent guideline has been put forth. This mandates the physician to take a more aggressive approach to the treatment of lipid disorders with a basic understanding as outlined above. The physician now has the medications at his or her disposal to meet the challenge of these more stringent guidelines.

1. Keys A, Aravanis C, Blackburn H, et al: Probability of middle-aged men developing coronary heart disease in five years. Circulation 1972;45:815-828.

2. Martin MJ, Browner WS, Hulley SB, et al: Serum cholesterol, blood pressure, and mortality: Implications from a cohort of 361,622 men. Lancet 1986;2:933-936.

3. Kannel WB, Castelli, WP: Cholesterol in the prediction of atherosclerotic disease: New perspectives based on the Framingham study. Ann Intern Med 1979:90:85-91.

4. Report of the National Cholesterol Education Program Expert Panel on Detection, Evaluation and Treatment of High Blood Cholesterol in Adults. Arch Intern Med 1988;148:36-69.

5. Newman WP, Freedman DS, Voors AW, et al: Relation of serum lipoprotein levels and systolic blood pressure to early atherosclerosis: The Bogalusa Heart Study. N Engl J Med 1986;314:138-144.

6. Lipid Research Clinics Program: The Lipid Research Clinics Coronary Primary Prevention Trials results: II. The relationship of reduction in incidence of coronary heart disease to cholesterol lowering. JAMA $1984 ; 251: 365-374$.

7. Lesko RM, Abbey DE: Elevated serum cholesterol values preceding myocardial infarction: The need for physician referral to lipid education. JAOA 1987;87:36-39.
8. Frohlich J: Hyperlipoproteinemias. (Personal communication).

9. Goldstein JL, Albers JJ, Hazzard WR, et al: Genetic and medical significance of neonatal hyperlipdemia, abstract. $J$ Clin Invest 1973;52:35a

10. Berg K: Genetics of coronary heart disease, in Steinberg A, Barn A, Motulsky A, et al (eds): Progress in Medical Genetics. Philadelphia, WB Saunders Co, 1983, vol 5.

11. Golper TA: Therapy for uremic hyperlipdemia. Nephron 1984;38:217225.

12. Patsch JR, Patsch W: Exercise, high density lipoproteins, and fat tolerance. Compr Ther 1984;10:29-37.

13. Schaefer EJ, Levy RI: Pathogenesis and management of lipoprotein disorders. N Engl J Med 1985;312:1300-1310.

14. Nikkila EA: Familial lipoprotein lipase deficiency and related disorders of chylomicron metabolism, in Stanbury JB, Wyngaarden JB, Fredrickson DS, et al (eds): The Metabolic Basis of Inherited Disease, ed 5. New York, Mc Graw-Hill Book Co, Inc, 1983, pp 665-671.

15. Goldstein JL, Brown MS: Lipoprotein receptors: Genetic defense against atherosclerosis. Clin Res 1982;30:417-426.

16. Goldstein JL, Hazzard WR, Schrott HG, et al: Hyperlipidemia in coronary heart disease: I. Lipid levels in 500 survivors of myocardial infarction. $J$ Clinc Invest 1973;52:1533-1543.

17. Knopp, RH, Walden CE, Heiss G, et al: Prevalence and clinical correlates of beta-migrating very-low-density lipoprotein: Lipid Research Clinics Program Prevalence Study. Am J Med 1986;81:493-502.

18. Chait A, Albers JJ, Brunzell JD: Very low density lipoprotein overproduction in genetic forms of hypertriglyceridemia. Eur $J$ Clin Invest 1980;10:17-20.

19. Kesaniemi YA, Grundy SM: Dual defect in metabolism of very-lowdensity lipoprotein triglycerides: Patients with type 5 hyperlipoproteinemia. JAMA 1984;251:2542-2547.

20. Counseling the Patient with Hyperlipidemia. Dallas, American Heart Association, 1984.

21. Grundy SM: Comparison of monounsaturated fatty acids and carbohydrates for lowering plasma cholesterol. N Engl J Med 1986;314:745748.

22. Kushi LH, Lew RA, Stare FJ, et al: Diet and 20-year mortality from coronary heart disease: The Ireland-Boston Diet Heart Study. $N$ Engl $J$ Med 1985;312:811-818.

23. Arntzenius AC, Kromhout D, Barth JD, et al: Diet, lipoproteins, and the progression of coronary atherosclerosis: The Leiden Intervention Trial. N Engl J Med 1985;312:805-810.

24. Samuel P, McNamara DJ, Shapiro J: The role of diet in the etiology and treatment of atherosclerosis. Ann Rev Med 1983;34:179-194.

25. Illingworth DR: Lipid-lowering drugs: An overview of indications and optimum therapeutic use. Drugs 1987;33:259-279.

26. Lavie GJ, Gav GT, Squires RW, et al: Management of lipids in primary and secondary prevention of cardiovascular disease. Mayo Clin Proc 1988;63:605-621.

27. Coronary Drug Project Research Group: Clofibrate and niacin in coronary artery disease. JAMA 1975;231:360-381.

28. Phillipson BE, Rothrock DW, Cannon WE, et al: Reduction of plasma lipids, lipoproteins, and apoproteins by dietary fish oils in patients with hypertriglyceridemia. $N$ Engl J Med 1985;312:1210-1216.

29. Riskind BM: Gemfibrozil, lipids, and coronary risk, editorial. NEngl J Med 1987;13:1279-1281.

30. Fricke MH, Elo O, Haapa K, et al: Helsinki Heart Study: Primary Prevention Trial with gemfibrozil in middleaged men with dyslipidemia. N Engl J Med 1987;317:1237-1245.

31. Kromhout D, Bosschieter EB, de Lezenne C: The inverse relation between fish consumption and 20-year mortality from coronary heart disease. N Engl J Med 1985;312:1205-1209.

32. Shaefer EJ: Clinical, biochemical, and genetic features in familial disorders of high density lipoprotein deficiency. Arteriosclerosis $1984 ; 4: 303-322$.

From the Heart Disease Prevention Clinic, Department of Medicine, Texas College of Osteopathic Medicine, Fort Worth, Tex.

Reprint requests to Dr Bleicher, TCOM, 999 Montgomery, Fort Worth, TX 76107. 